\title{
Obtaining Patient Information and Anxiety in Novice Nursing Students During the First Clinical Rotation
}

\author{
Kobayashi Akiko \\ Department of Nursing, Biola University, 13800 Biola Avenue, La Mirada, California 90639, USA
}

\begin{abstract}
Article Details
Article Type: Research Article

Received date: $29^{\text {th }}$ May, 2019

Accepted date: $24^{\text {th }}$ June, 2019

Published date: $04^{\text {th }}$ September, 2019

*Corresponding Author: Kobayashi Akiko, Department of Nursing, Biola University, 13800 Biola Avenue, La Mirada, California 90639, USA. E-mail: akiko.kobayashi@biola.edu

Citation: Kobayashi A (2019) Obtaining Patient Information and Anxiety in Novice Nursing Students During the First Clinical Rotation. J Comp Nurs Res Care 4: 143. doi: https://doi.org/10.33790/jcnrc1100143.

Copyright: (C2019, This is an open-access article distributed under the terms of the Creative Commons Attribution License 4.0, which permits unrestricted use, distribution, and reproduction in any medium, provided the original author and source are credited.
\end{abstract}

\begin{abstract}
Background: Gathering comprehensive patient information at the beginning of the shift is essential for effective nursing practice. Novice nursing students (NSs) feel highly anxious, and obtaining patient information is a challenge. There is limited knowledge regarding the ability of novice NSs to gather essential patient information from the previous shift. This study was conducted to assess the anxiety levels of novice NSs and the types of patient information obtained by them and sources that NSs utilized when they obtained patient information.
\end{abstract}

Methods: The anxiety levels of NSs were compared between the beginning, midpoint and the end of the first clinical rotation. The patient information items that NSs obtained and the sources that NSs utilized were also compared between these assessment points.

Results: As anticipated, the anxiety levels were the highest on the first day and progressively decreased throughout the first rotation. As for the gathering of patient information from the previous shift, progressively increased numbers of NSs obtained early morning laboratory data, and the majority of NSs obtained them by the end of the first rotation. A steady increase was also seen in obtaining vital signs (VSs) from the previous shift but the number did not reach $100 \%$ of NSs even on the last clinical day. Less than half of the NSs obtained the previous shift's patients' pain levels throughout the rotation. The computer use was consistently the most popular source of patient information. There was no increase in utilization of RNs, either day-shift or night-shift as the information source during the rotation.

Conclusions: The novice NSs did not show consistent improvement in gathering essential patient information during the first clinical rotation. It is important to remind NSs to obtain all essential patient information periodically and to encourage them to obtain patient information from the shift report.

\section{Introduction}

Gathering appropriate patient information is always essential for effective clinical practice for nursing students (NSs). Patient information will help them identify the focus of the initial assessment and the nursing diagnoses for care plans to provide appropriate care for the assigned patients. It is difficult for novice NSs who have little or no previous clinical experience to know what patient information is essential to obtain at the beginning of the clinical day. Obtaining the essential information is particularly difficult when NSs' anxiety levels are high in an unfamiliar clinical environment during their first clinical rotation.

Novice NSs feel highly anxious during their first clinical rotation due to limited clinical experiences and knowledge [1, 2]. Literature indicated that a high anxiety level in NSs would affect their clinical performances. A seminal study by Kleehammer et al. [3] found that anxiety levels in the first year for NSs was most often associated with the fear of making mistakes, as well as the execution of unfamiliar clinical procedures and use of hospital equipment [3]. Their analysis also showed that juniors experienced a significantly higher level of anxiety than their senior students. Chernomas et al. [4] conducted a similar study and examined the effects of stress, depression and anxiety on NSs [4]. Results pointed to ineffective coping strategies and high expectations of academic and clinical performance to be the potential causes of increased anxiety scores. During this study, NSs also expressed feelings of unpreparedness and anxiety, before, during and after clinical practice, revealing the clinical setting as a stimulus for stress and anxiety [4]. These results are consistent with a study conducted by Cheung et al. [5], which focused on anxiety in the clinical setting and the effects of anxiety on nursing student performance. Results revealed that an increase in performance errors was associated with an increase in anxiety levels [5]. This study may further indicate that novice NSs have difficulty paying attention and maintaining focus on the tasks they perform when feeling anxious.

There is limited knowledge about how proficient novice NSs are in obtaining previous shift's information on their patients and what resources NSs utilize when their anxiety levels are high. According to Skaalvik et al. [6], oral shift report is an important and essential learning opportunity for NSs, serves several purposes, and provides an opportunity for professional communication that supports both educational and social functions for NSs during clinical practice [6]. However, obtaining patient information during a fast-paced shift report with unfamiliar terminology in an unfamiliar clinical environment can cause feelings of insecurity in novice NSs.

One hypothesis is that novice NSs with high level of anxiety may choose the electronic health record (EHR) as their resource to obtain patient information. In fact, one study supported this hypothesis and 
stated that a prevalent way for NSs to obtain patient information within the clinical setting was using EHR [7]. This study revealed that $50 \%$ of nursing students obtained patient information through EHR. With the influx and overwhelming prevalence of documentation done on a computer, it is very likely that novice NSs with a high level of anxiety may be obtaining a large portion of clinical information electronically rather than through face-to-face communication, due to lack of confidence to approach RNs.

In order to guide novice NSs at the clinical settings, providing them structured instructions and clear clinical expectations is important prior to the initial clinical experiences to reduce anxiety levels [8]. Considering a high level of anxiety, novice NSs have received various instructional guidelines during the first clinical rotation. A study revealed that among Turkish novice NSs, a weak correlation was identified between the level of anxiety and the amount of clinical preparatory education given before the first clinical experience [8]. Another study revealed that a peer mentoring system between experienced NSs and novice NSs showed a decrease in clinical situation-specific anxiety compared with students who were not peer mentored [9]. Peer mentoring consists of experienced and novice NSs spending the clinical day working together to care for assigned patients by performing clinical skills, communicating with $\mathrm{RN}$, and using clinical reasoning [9]. Learning from non-licensed NSs at a hospital, however, may be complex, requiring negotiations and clarifications about liability and legislation with the hospital. Peer mentoring by senior NSs in the Skills Laboratory practices, on the other hand, may provide positive learning experiences for novice NSs in a safe, encouraging and familiar environment of the skills laboratory. Additionally, the peer mentoring model can also provide senior NSs with leadership experience.

In the BSN program at Biola University, novice NSs receive various clinical guidelines. One of them is the Clinical Expectations guidelines. The specific and measurable clinical expectations are delineated in the areas of Nursing Skills, Physical Assessment, Communications, Critical Thinking, and Spiritual Care. These clinical expectations were originally created to provide consistency among multiple clinical instructors during the first clinical semester, so that all novice NSs, regardless of the instructor, had the common goals to achieve by the end of the first rotation. The second set of guidelines is the Critical Value sheet. Since NSs in the first clinical semester have not taken a pharmacology course, they need guidelines for safe and accurate ways to prepare and administer medication. This sheet helps them obtain specific clinical information about the patient prior to preparation of the medication. Students are also expected to complete a comprehensive summary of the assigned patient, called Nursing Process Analysis, in addition to developing a care plan on their patients for each clinical day. With these preparations, clinical faculty were confident that novice NSs were well prepared for their first clinical practicum and that their clinical learning was enriched. However, as for obtaining the previous shift's patient information prior to NSs' first visit to their assigned patients in the morning, each clinical instructor guided their NSs based on the instructor's own experiences and ideas without specific guidelines regarding what patient information NSs should obtain and what resources NSs might use.

The purposes of the study were to identify anxiety levels of novice NSs at a clinical site during the first clinical rotation and to acquire data on the types of patient information that novice NSs would obtain prior to their first visit to the assigned patients in the morning. It was hypothesized that at the beginning of the first clinical rotation, when anxiety levels were expectedly at their highest, novice NSs would gather minimal patient information but would gradually obtain more complete information, as anxiety levels decreased and as NSs became more familiar with the clinical environment. This report presents the expected and unexpected findings of the study, along with the consequent recommendations. The application of the results of this study may contribute to better clinical learning outcomes for novice NSs through guiding them in obtaining essential patient information despite their anxiety levels caused by limited knowledge and unfamiliar clinical environments.

\section{Methods}

Forty novice NSs in the first clinical semester, which is the fifth semester of the BSN program, participated in the study. They have completed four semesters of general education required for the program, and now in the first clinical semester, students have just begun learning basic nursing skills and pathophysiology. Prior to the clinical, students were oriented to the rotation including the introduction to clinical expectations and documentation that NSs were expected to complete each clinical week. Novice NSs also received a thorough introduction to the facility during the clinical orientation.

The NSs were randomly divided into four groups. Each clinical group had ten students with one clinical instructor, and the groups were assigned either to a surgical, respiratory medical, oncology, or medical neurology unit within an urban community hospital. Each group stayed on the same unit throughout the rotation. The rotation comprised two 6-hour clinical days per week for the first three weeks, then one 8.5-hour clinical day per week for the following five weeks, excluding pre- and post-conferences. The clinical shift started at 7:00 am, after one hour of preconference. Students were assigned to different patients on each clinical day except on the second consecutive clinical day, if the same patients were available during the first three weeks. Each clinical instructor selected the patient assignment for the students within the group (one patient per student). During one hour of preconference, NSs spent about half an hour studying the pathophysiology associated with the diagnoses of their assigned patients.

The university's Protection of Human Rights in Research Committee (PHRRC), which is equivalent to Institute of Review Board, approved the study beforehand. Confidentiality and privacy of participating NSs were strictly maintained through the use of pseudonyms. The primary investigator (PI) for this study was not included as the clinical instructor in any of the clinical groups.

To measure the level of anxiety, the State Trait Anxiety Inventory (STAI) was utilized. The permission to reproduce the STAI form was received and the inventory was purchased from Mind Garden Publisher. The STAI has been widely used to assess anxiety levels among diverse groups of adults and children $[10,11]$. The students took the STAI survey during preconference on the first clinical day, the fifth day (the midpoint) and the tenth (the last) clinical day. A Paired T test was used for the comparisons of the mean STAI scores within the cohort of 40 students between the first and fifth day clinical day and between the fifth and the tenth clinical day.

The Patient Information Questionnaire (PIQ) was created to ask NSs to indicate types of patient information of the previous shift that they obtained prior to their first visit to their assigned patient in the morning. The students took the PIQ at the end of the clinical day during the post conference on the designated days when they took STAI during the preconference. The PIQ collected both the demographic data and clinical data. The demographic data included the patient's age/date of birth, diagnosis/surgical procedure, isolation status, and allergies. The clinical data included 6:00 am vital signs, pain level, $\mathrm{O} 2$ saturation, intake and output (I/O), early morning laboratory results, quality of sleep during the previous night, abnormal events during the night, interventions taken for abnormal events, and PRN medication and the results. In addition to types of patient information, PIQ also asked NSs to indicate sources of patient information that they obtained from (See PIQ sheet in Appendix). Descriptive statistics was used to compare numbers of students who obtained each type of patient information. 


\section{Results}

\section{Anxiety Scores}

Among the forty novice NSs participated, there were 38 female and two male NSs with an average age of 20.8 years old. The STAI scores ranged from 10 (the lowest anxiety level) to 40 (the highest level). Table 1 shows the NSs' mean STAI scores per clinical unit over the course of the semester. There are small variations in the mean STAI scores between clinical groups but the differences were not significant. On the first clinical day, the highest STAI score was 27.6 (oncology unit group) while the lowest was 23.0 (surgical unit group). The mean STAI scores for students on the oncology unit were consistently the highest among the four clinical groups throughout the semester. The mean STAI score of all 40 students was 25.3 on the first clinical day. The mean STAI scores of all NSs decreased significantly from first to fifth day $(25.3,19.8$, respectively. $\mathrm{p}<$
$0.0001)$ and from the fifth to tenth day $(19.8,17.4$, respectively. $p<$ $0.0001)$.

\section{Obtaining previous shift's patient information}

As for the patient information, the numbers of NSs who obtained patient information items (clinical category) are shown in Table 2. The numbers of NSs, who obtained 6:00 am I/O, vital signs, oxygen saturation, and the early morning laboratory results prior to NSs' first visits to their assigned patients, showed a steady increase over time. Especially the number of NSs who obtained the early laboratory results increased from $13(32.5 \%)$ on the first clinical day to 35 $(87.5 \%)$ on the last clinical day. On the other hand, there was no progression in the number of NSs who obtained the previous shift's pain levels of their assigned patients, and consistently less than half $(40 \%)$ of the novice NSs obtained the pain levels throughout the clinical rotation (Table 2).

\begin{tabular}{|c|c|c|c|}
\hline Clinical units & $\begin{array}{l}\text { 1st day of clinical } \\
\text { Mean }+/-S D\end{array}$ & $\begin{array}{l}\text { 5th day of clinical } \\
\text { 1st day of clinical } \\
\text { Mean+/-SD }\end{array}$ & $\begin{array}{l}\text { 10th day of clinical } \\
\text { Mean+/-SD }\end{array}$ \\
\hline $\begin{array}{l}\text { Neurology unit } \\
(\mathrm{N}=10)\end{array}$ & $24.8+/-4.02$ & $20.0+/-4.90$ & $18.6+/-4.58$ \\
\hline $\begin{array}{l}\text { Oncology unit } \\
(\mathrm{N}=10)\end{array}$ & $27.6+/-6.07$ & $21.9+/-5.17$ & $20.1+/-4.11$ \\
\hline $\begin{array}{l}\text { Respiratory unit } \\
(\mathrm{N}=10)\end{array}$ & $25.8+/-7.13$ & $18.1+/-3.21$ & $14.4+/-3.17$ \\
\hline $\begin{array}{l}\text { Surgical unit } \\
(\mathrm{N}=10)\end{array}$ & $23.0+/-4.45$ & $19.1+/-3.55$ & $16.5+/-3.68$ \\
\hline $\begin{array}{l}\text { The total mean } \\
(\mathrm{N}=40)\end{array}$ & $25.3+/-5.68$ & $19.8+/-4.42$ & $17.4+/-4.41$ \\
\hline P Values & & $\begin{array}{l}\mathrm{P}<0.0001 \text { (Between 1st day and } \\
\text { 5th day) }\end{array}$ & $\begin{array}{l}\mathrm{P}<0.0001 \text { (Between 5th day and 10th } \\
\text { day) }\end{array}$ \\
\hline
\end{tabular}

Table 1. The mean STAI scores for the novice NSs on all units on the first, fifth and tenth clinical days. (Range 10-40)

\begin{tabular}{|c|c|c|c|}
\hline & 1st Clinical Day (N=40) & 5th Clinical Day (N=40) & 10th Clinical Day (N=40) \\
\hline $\begin{array}{c}6 \mathrm{am} \\
\text { Intake/Output }\end{array}$ & $9(22.5 \%)$ & $11(27.5 \%)$ & $17(42.5 \%)$ \\
\hline $\begin{array}{c}6 \mathrm{am} \\
\text { Vital Signs }\end{array}$ & $20(50 \%)$ & $25(62.5 \%)$ & $32(80 \%)$ \\
\hline $\begin{array}{c}6 \text { am } \\
\text { O2 saturation }\end{array}$ & $17(42.5 \%)$ & $22(55 \%)$ & $28(70 \%)$ \\
\hline $\begin{array}{c}\text { Early AM } \\
\text { Laboratory Results }\end{array}$ & $13(32.5 \%)$ & $29(72.5 \%)$ & $35(87.5 \%)$ \\
\hline $\begin{array}{c}6 \text { am } \\
\text { Pain Level }\end{array}$ & $16(40 \%)$ & $16(40 \%)$ & $16(40 \%)$ \\
\hline Sleep Quality & $21(52.5 \%)$ & $23(57.5)$ & $25(62.5 \%)$ \\
\hline
\end{tabular}

\section{Sources of patient information}

For the resources that NSs used to obtain patient information, NSs were asked to make one check mark for one source per one patient information item on the PIQ. Some of the NSs marked more than one source for one patient information item obtained. For statistical purposes, "1.0" was divided by the number of sources marked. Therefore each source was assigned a fraction. When all the fractions were added together, they added to 1.0. For example if the student selected 2 sources for 1 patient information item, each received 0.5 points so that the total for that student for that item was still 1.0.

By using the above formula, Table 3 shows the overall summary of the relative use of the sources that the novice NSs used to gather patient information. The range is from " 0 " if no student used the source for any item of the patient information to " 40 " if every student used the source for every item of the patient information. The EHR use was consistently the most popular source for all types of patient information throughout the rotation. The relative use of the night-shift $\mathrm{RN}$ (face-to-face shift report) as the source of patient information did not increase over time $(6.0,6.0,5.8$, respectively) even though the anxiety scores were significantly lower at each assessment point. A similar trend was seen in the relative use of their assigned day-shift $\mathrm{RN}$ at each assessment point (3.8, 2.0, 1.8 , respectively). 


\begin{tabular}{|l|l|l|l|}
\hline & 1st Clinical Day & 5th Clinical Day & 10th Clinical Day \\
\hline Night RN & $6.0(15 \%)$ & $6.0(15 \%)$ & $5.8(14.4 \%)$ \\
\hline Day RN & $3.8(9.2 \%)$ & $2.0(5 \%)$ & $1.8(4.6 \%)$ \\
\hline EHR & $9.0(22.4 \%)$ & $13.3(33.3 \%)$ & $18(45 \%)$ \\
\hline Patient/Family & $1.2(3 \%)$ & $2.4(6 \%)$ & $4.2(10.6 \%)$ \\
\hline Other & $1.7 \%(4.2 \%)$ & $1.1(2.7 \%)$ & $1.3(3.2 \%)$ \\
\hline
\end{tabular}

Table 3: Comparison of relative use of the sources by students to obtain patient information

\section{Conclusions}

Obtaining patient information prior to taking care of the assigned patients is essential for valid nursing practice. It has been reported that novice NSs have high anxiety levels during their first clinical rotation but little research has been done to discover how and what patient information novice NSs obtain when their anxiety is very high. This study was conducted to identify novice NSs' anxiety levels during clinical rotations and their ability to obtain essential patient information during the first clinical semester.

As expected, NSs' anxiety level was the highest at the beginning of their first clinical rotation. The levels of anxiety steadily decreased over time even from the middle to the end of the semester. This consistent decrease may be due to gaining more clinical experiences, learning more of the skills and knowledge required in nursing care and having increased confidence and familiarization with the clinical environment, as discussed by [3].

The results of the types of patient information gathered by NSs in the early morning revealed that more novice NSs gathered essential information over time during the first clinical rotation. Of all the patient clinical information items, obtaining early morning laboratory data particularly showed a steady increase over time, and the majority of novice NSs were able to obtain them by the end of the first clinical rotation. The results may indicate that novice NSs were rapidly developing and applying initial stage of critical thinking by obtaining the recent lab values to understand the condition of the patient. It may also indicate that through continued theory lectures, multiple care plans that students wrote weekly, and clinical experiences guided by instructors, students were developing their interpretive skills, thereby leading them to gather lab values as compared with the beginning of the semester.

While there was no decrease in the amount of patient information obtained throughout the semester, it was startling to discover that there was little to no improvement in obtaining several items. The most critical finding was the lack of student growth in obtaining the pain level of their assigned patient prior to the first visit to the patient. Despite the clinical guidelines provided for novice NSs and clinical faculty's consistent assistance for each novice NS, this finding indicated that NSs were not prepared to assess pain levels prior to the first visit. This was completely unexpected by the clinical faculty and the PI. Pain management is a crucial component of the nursing profession, to the degree that pain is considered the sixth vital sign. Additionally, though there was a gradual increase in the number of NSs who obtained the previous shift's vital signs prior to providing patient care, the number did not reach $100 \%$ of the students at the end of first clinical semester. These results reveal a gap between student knowledge and clinical practice, which needs to be bridged through further instruction on the import of these data points for the creation and implementation of comprehensive patient care plans.

In regards to the sources used for obtaining patient information, the EHR system was consistently the most popular source for all types of patient information regardless of anxiety levels throughout the rotation. The popular use of EHR as a source of patient information supports the previous report [7]. Once NSs learned the specific EHR system of the hospital, it provided NSs with patient information that they needed without interacting with RNs. The current generation of NSs has been exposed to and incorporated computer technologies in their everyday lives, potentially contributing to their frequent reliance on EHR as a source of patient information. This generation of NSs may also have hesitancy communicating face to face with RNs as they commonly interact with others via text messages and other forms of digital communication. In addition, NSs in the first clinical rotation may perceive RNs as busy and evasive, contributing to their anxiety and insecurity when interacting face to face with RNs.

In comparison to EHR use, the number of NSs who utilized the night-shift $\mathrm{RN}$ or the shift report did not show any increase over time despite the reduction in anxiety. The events that occurred during the previous shift may not have been fully recorded in the EHR system by RNs in the previous shift by the time NSs view the EHR in the early morning. Therefore, NSs may have missed critical information about their assigned patients if NSs depend solely on EHR as the source of patient information, without conferring with the RNs.

The results of this study confirmed the previous reports on high anxiety levels among novice NSs during their first clinical rotation and provided a new set of meaningful data on how and what patient information novice NSs obtained prior to their visits to the assigned patients. Both expected and unexpected findings of this study led us to revisit the current education on clinical preparation for novice NSs. Details for future applications are discussed next.

\section{Limitations of the Study}

The population in this study was mainly the BSN students who came straight from high schools. Therefore the results maybe applicable to younger BSN students and not to LVN students studying for BSN or students in an ADN to BSN program. Also there may be a threat to an external validity of maturation in the trend of obtaining patient information over time. A steady decrease of anxiety among novice NSs may also have contributed to the trend of their ability to obtain more patient information as discussed in the Conclusion.

\section{Applications and Recommendations}

As the results of this study, several recommendations were identified to assist novice NSs in obtaining essential information of the patients from the beginning of their clinical rotation. First, it is recommended to provide a set of standardized guidelines for novice NSs to obtain essential patient information. Using this type of guidelines would not only train and guide students as they shift through patient information, but the standardized guidelines may also decrease NSs' anxiety levels as the guidelines give students an explicit direction on what patient information to obtain. To introduce these guidelines for novice NSs, a simplified patient information obtaining sheet commonly referred to as the "brain"-is created and is currently being implemented to improve the gathering of patient information. 
Secondly, it is important to educate novice NSs to think of the reasons why obtaining patient information is necessary prior to caring their patients and what clinical information items are essential. Understanding the importance of obtaining pertinent patient information will encourage and remind novice NSs to gather the necessary data prior to their visits to the assigned patients. Having a simplified brain in hand will help novice NSs obtain essential patient information. Knowing the assigned patients better will also help NSs start an appropriate conversation with their patients during their visit and it may lead to an improved rapport with the patients. In addition, having relevant patient information will help NSs do appropriately focused assessment on their patients and identify potential nursing diagnoses. Early identification of a nursing diagnosis will help NSs provide proactive care for their patients.

Educating novice NSs about the importance of obtaining patient information and providing them with a "brain" will also lead to a consistent clinical teaching model for novice NSs who are instructed by different clinical instructors. Further research is recommended and a study is currently being conducted to measure the effectiveness of utilizing a simplified brain on the consistency in clinical teaching of gathering patient information.

Thirdly, as novice NSs' anxiety levels decrease and NSs learn more pathophysiology and complex medical terminology in their theory courses over time, it is important to encourage them to obtain patient information from the shift report, as discussed previously [6]. Registered nurses from the previous shift may have more detailed, pertinent, and complete information on the events occurred on the patients during the previous shift that may not yet have been recorded in EHR.

This study results opened eyes of clinical instructors to student needs: Even though a thorough pre-clinical education and introductory materials were provided to novice NSs, the results indicated that novice NSs needed further guidelines on obtaining pertinent patient information prior to their first visit to the assigned patients. The results of this study will contribute to the improvement of clinical education for novice NSs to maximize their learning outcomes and providing proactive patient care as early as during the first clinical rotation.

\section{Acknowledgements}

I would like to acknowledge Dr. Anne Gewe, who supported the revision of this manuscript, and clinical instructors, Glenn Styffe, Katie Thede, Kate Estes and Jenna Buckley who collaborated in this study through data collection from NSs. I would also like to acknowledge senior BSN students, Soorin Hong, Sarah Kim, Nataleigh Maia, Aimee Nelson, Nataly Mehne, and Aleksandra Banas from Biola University, who contributed to the literature review, data entry and statistical analyses of the complex data set for this study as a part of their project in the Applied Nursing Research course.

\section{References}

1. Bayoumi MM, Elbasuny MM, Mofereh AM, Assiri, MA, \& Al fesal AH (2012) Evaluating Nursing Students' Anxiety and Depression during Initial Clinical Experience. International $\mathrm{J}$ Psychol Behav Sciences, 2: 277-281.

2. Sun FK, Long A, Tseng YS, Huang HM, You JH, et al. (2016) Undergraduate Student Nurses' Lived Experiences of Anxiety During Their First Clinical Practicum: A Phenomenological Study. Nurse Education Today, 37: 21-26.

3. Kleehammer K, Hart A, Keck J (1990) Nursing students' perceptions of anxiety-producing situations in the clinical setting. J Nurs Edu 29: 183-187.

4. Chernomas WM, Shapiro C (2013) Stress, Depression, and Anxiety among Undergraduate Nursing Students. Int J Nurs
5. Cheung RY, Au TK (2011) Nursing Students' Anxiety and Clinical Performance. J Nurs Edu, 50: 286-289 .

6. Skaalvik MW, Normann HK, Henriksen N (2010) To what extent does the oral shift report stimulate learning among nursing students? A qualitative study. Journal of Clinical Nursing, 19: 2300-2303.

7. Scott SD, Gilmour J, Fielden J (2008) Nursing students and Internet health information. Nurse Education Today, 28: 9931001.

8. Baksi A, Gumus F, Zengin L (2017) Effectiveness of the preparatory clinical education on nursing students anxiety: A randomized controlled trial. Int J Caring Sciences 1003.

9. Walker D, Verklan T (2016) Peer mentoring during practicum to reduce anxiety in first semester nursing students. J Nurs Education, 55: 651-654.

10. O'Roark AM, Prieto JM, Brunner TM (2014) Obituaries: Charles Donald Spielberger (1927-2013). American Psychologist, 69: 297-298.

11. Julian LJ (2011) Measures of Anxiety: State-Trait Anxiety Inventory (STAI), Beck Anxiety Inventory (BAI), and Hospital Anxiety and Depression Scale-Anxiety (HADS-A). Arthritis Care \& Research, 63: S467-S472. 


\section{Appendix PIQ}

Questionnaire on clinical shift report experience Level 1 Fall Semester Clinical Practicum, X University

Today's date:

clinical Unit:

Student's secret code (favorite animal + number):

Please fill out the following information you have/haven't received on your assigned patient before your first visit to the patient:

If you circled yes, Where did you get the information from? (please indicate by putting a checkmark)

\begin{tabular}{|c|c|c|c|c|c|c|c|}
\hline & & $\begin{array}{c}\text { Night } \\
\text { Shift RN }\end{array}$ & $\begin{array}{c}\text { Your } \\
\text { Assigned } \\
\text { Day RN }\end{array}$ & $\begin{array}{l}\text { Patient's } \\
\text { Chart in } \\
\text { Computer }\end{array}$ & $\begin{array}{l}\text { Patient } \\
\text { and/or } \\
\text { family }\end{array}$ & $\begin{array}{l}\text { Other: } \\
\text { PT, OT, } \\
\text { CNA, RT, } \\
\text { physician }\end{array}$ & $\begin{array}{l}\text { Descriptions: } \\
\text { No need to fill out where } \\
\text { grayed }\end{array}$ \\
\hline Pt's name & $\begin{array}{l}\text { Yes } \\
\text { No }\end{array}$ & & & & & & \\
\hline Admission date & $\begin{array}{l}\text { Yes } \\
\text { No }\end{array}$ & & & & & & \\
\hline Pt's Age/DOB & $\begin{array}{l}\text { Yes } \\
\text { No }\end{array}$ & & & & & & \\
\hline Gender & $\begin{array}{l}\text { Yes } \\
\text { No }\end{array}$ & & & & & & \\
\hline Diagnosis/Procedure & $\begin{array}{l}\text { Yes } \\
\text { No }\end{array}$ & & & & & & \\
\hline Isolation/Precaution & $\begin{array}{l}\text { Yes } \\
\text { No }\end{array}$ & & & & & & \\
\hline Allergy & $\begin{array}{l}\text { Yes } \\
\text { No }\end{array}$ & & & & & & \\
\hline
\end{tabular}




\begin{tabular}{|c|c|c|c|c|c|c|c|}
\hline 6 am vital signs & $\begin{array}{l}\text { Yes } \\
\text { No }\end{array}$ & & & & & & \\
\hline \multirow[t]{2}{*}{6 am 02 saturation } & Yes & & & & & & \\
\hline & & $\begin{array}{l}\text { Night } \\
\text { Shift RN }\end{array}$ & $\begin{array}{c}\text { Your } \\
\text { Assigned } \\
\text { Day RN }\end{array}$ & $\begin{array}{l}\text { Patient's } \\
\text { Chart in } \\
\text { Computer }\end{array}$ & $\begin{array}{l}\text { Patient } \\
\text { and/or } \\
\text { family }\end{array}$ & $\begin{array}{l}\text { Other: } \\
\text { PT, OT, } \\
\text { CNA, } \\
\text { physician }\end{array}$ & Descriptions: \\
\hline $\begin{array}{c}\text { 6am intake and } \\
\text { output }\end{array}$ & $\begin{array}{l}\text { Yes } \\
\text { No } \\
\end{array}$ & & & & & & \\
\hline 6 am pain level & $\begin{array}{l}\text { Yes } \\
\text { No }\end{array}$ & & & & & & If, yes what pain level? \\
\hline $\begin{array}{l}\text { How patient slept } \\
\text { during last night }\end{array}$ & $\begin{array}{l}\text { Yes } \\
\text { No }\end{array}$ & & & & & & \\
\hline $\begin{array}{c}\text { Abnormal events at } \\
\text { night }\end{array}$ & $\begin{array}{l}\text { N/A } \\
\text { Yes } \\
\text { No }\end{array}$ & & & & & & if yes, describe in description \\
\hline $\begin{array}{l}\text { Interventions taken } \\
\text { for abnormal events }\end{array}$ & $\begin{array}{l}\text { N/A } \\
\text { Yes } \\
\text { No }\end{array}$ & & & & & & $\begin{array}{l}\text { If yes, describe what } \\
\text { interventions }\end{array}$ \\
\hline Lab results & Yes & & & & & & \\
\hline $\begin{array}{l}\text { PRN medication } \\
\text { given by night shift }\end{array}$ & $\begin{array}{l}\text { N/A } \\
\text { Yes } \\
\text { No }\end{array}$ & & & & & & Ifyes, describe \\
\hline
\end{tabular}

